\title{
Monitoring the characteristics of cultivable halophilic microbial community during salted-ripened anchovy (Engraulis anchoita) production
}

\author{
Perez Silvina $^{\mathrm{a}, *}$, Czerner Marina ${ }^{\mathrm{a}, \mathrm{b}}$, Patat María Laura ${ }^{\mathrm{c}}$, Zaritzky Noemí Elisabet ${ }^{\mathrm{d}, \mathrm{e}}$, \\ Murialdo Silvia Elena ${ }^{\mathrm{b}, \mathrm{f}}$, Yeannes María Isabel ${ }^{\mathrm{a}, \mathrm{b}}$ \\ ${ }^{\text {a }}$ Consejo Nacional de Investigaciones Científicas y Técnicas (CONICET), Argentina \\ ${ }^{\mathrm{b}}$ Dpto. de Ingeniería Química y en Alimentos, Facultad de Ingeniería, UNMDP, Argentina \\ ${ }^{\mathrm{c}}$ Dpto. de Matemática, Facultad de Ciencias Exactas y Naturales, UNMDP, Argentina \\ d Centro de Investigación y Desarrollo en Criotecnología de Alimentos (CIDCA), Facultad de Ciencias Exactas, UNLP-CONICET, Argentina \\ e Dpto. de Ingeniería Química, Facultad de Ingeniería, UNLP, Argentina \\ ${ }^{\mathrm{f}}$ Comisión de Investigaciones Científicas de la Prov. de Buenos Aires (CIC), Argentina
}

\section{A R T I C L E I N F O}

\section{Keywords:}

Fermented fish

Microbial ecology

Ripening

Multivariate analysis

\begin{abstract}
A B S T R A C T
The halophilic microbial community of the salted-ripened anchovy process was studied. Samples from raw materials (salt and fresh anchovies) and from the stages of brining and ripening were collected and analyzed for their bacterial counts at 15 and $20 \% \mathrm{NaCl}$. No halophilic colonies were found in fresh anchovy and counts of about $10^{3} \mathrm{CFU} / \mathrm{g}$ were determined in salt samples. A fluctuation of bacterial counts during the process was found. At the end of brining, $\sim 10^{4} \mathrm{CFU} / \mathrm{g}$ were determined in anchovy samples and this value was reduced to not detectable counts at the beginning of the ripening stage. After one month, counts increased to $\sim 10^{4} \mathrm{CFU} / \mathrm{g}$ and remained stable until the end of the process.

From each sample, colonies having different morphotypes were isolated and submitted to a macro and microscopic characterization, a study of salt requirement for growth, and biochemical and phenotypic tests. The results were submitted to Univariate, Bivariate and Multiple Correspondence Factorial Analysis (MCFA). A total of 79 colonies were isolated during the salting-ripening anchovy process. Among the isolates, about $40-50 \%$ was positive for indole production and lipolytic activity and a $25 \%$ showed ability to produce $\mathrm{H}_{2} \mathrm{~S}$ and proteolytic capacity. Proteolytic and lipolytic activities were well balanced along the process and resulted independent from the isolation stage, which is a desirable condition due to the contribution of microbial proteolysis and lipolysis to the development of texture and final aroma, respectively. $\mathrm{H}_{2} \mathrm{~S}$ and indole producers practically were not detected during ripening. This fact is important because indole and $\mathrm{H}_{2} \mathrm{~S}$ are associated with the development of off-flavors and spoilage in salted fish products. MFCA and Cluster Analyses complemented the Bivariate Analyses. The factor map showed proximity between the isolates from salt samples and from ripening. Isolates were statistically clustered in two groups. Cluster 1 grouped non-desirable activities $\left(\mathrm{H}_{2} \mathrm{~S}\right.$ and indole production) with cultures proceeding from brining whereas Cluster 2 related isolates mainly from salt samples and during ripening with some desirable microbial capacities (Cytochrome oxidase activity and non- $\mathrm{H}_{2} \mathrm{~S}$ and non-indole production). These results would indicate that during the ripening process of salted anchovies, a natural selection of beneficial microorganisms for the development of the typical product sensory attributes occurred.
\end{abstract}

\section{Introduction}

Foods behave like a dynamic system in which changes in $\mathrm{pH}$, atmosphere, nutrient composition and microbial community occur over time. The raw materials are initially contaminated with a wide variety of microorganisms and depending on the food processing parameters and subsequent storage conditions only a selection of these are able to colonize the food and grow. Despite the variation in the microbiota composition of fresh fish, marine products can be categorized into groups with similar microbial ecology (Gram and Dalgaard, 2002; Gram and Huss, 1996). That is the case of salted-cured fish products, such as anchovies, in which a natural fermentation -without starter cultures-

\footnotetext{
* Corresponding author at: Grupo de Investigación Preservación y Calidad de Alimentos (GIPCAL). Dpto. de Ingeniería Química y en Alimentos, Facultad de Ingeniería, Universidad Nacional de Mar del Plata. Juan B. Justo 4302, Mar del Plata 7600, Argentina.

E-mail address: silvinaperez@fi.mdp.edu.ar (S. Perez).
} 
occurs. Due to the high $\mathrm{NaCl}$ content and low water activity values that characterize this type of products, the microbiota is mainly constituted by halophilic or halotolerant microbes (Campello, 1985; Czerner and Yeannes, 2014; Felix et al., 2016; Hernández-Herrero et al., 1999a; Pérez et al., 2016; Pons-Sánchez-Cascado et al., 2005; Villar et al., 1985). Halophilic microbiota includes a great diversity of bacteria, archaea and eukaryote microorganisms able to survive and grow on hypersaline environments. According to their salt requirement, they can be classified into extreme halophiles (3.4-5.1 M NaCl), moderate halophiles $(0.85-3.4 \mathrm{M} \mathrm{NaCl})$ and halotolerants, capable to grow in the absence as well as in the presence of relatively high concentrations of salt (DasSarma and DasSarma, 2017).

Salting and ripening is a common and traditional practice used to preserve different small pelagic fish species such as herring, sprat and anchovy (Borgstrom, 1965; Madureira et al., 2009; Steffánson and Guðmundsdóttir, 1995). This type of products has firm consistency, reddish color, juicy texture, and a characteristic odor and flavor as a result of the physicochemical and enzymatic changes that take place during ripening, which can last from weeks to one year depending on the product. The enzymes that act during ripening may come from the fish tissue (endogenous enzymes) as well as from microbes (exogenous enzymes) (Campello, 1985; Besteiro et al., 2000; Hernández-Herrero et al., 1999b; Triqui and Reineccius, 1995). The mechanisms involved in the development of sensorial characteristics are not fully understood and the studies focused on the effect of the microbiological activity on the ripening process are limited. In this sense, some authors had suggested a microbial participation on the ripening process of salted anchovy (Hernández-Herrero et al., 1999a; Villar et al., 1985). More recently, Czerner and Yeannes (2014) determined that the ripening process is dominated by moderate halophilic bacteria, many of them with proteolytic, lipolytic and trimethylamine oxide reductase activities. These activities could contribute to the increase of non- protein nitrogen, free fatty acids and total volatile basic nitrogen contents, three indexes that show good correlation with both ripening time and sensory evaluation (Besteiro et al., 2000; Durand, 1981; Filsinger et al., 1982, 1984; Hernández-Herrero et al., 1999a; Pons-Sánchez-Cascado et al., 2005). On the other hand, more studies can be found in literature regarding extreme halophilic archaea and its relationship with salted fish spoilage (Felix et al., 2016; Gram and Huss, 1996) and the bacterial production of histamine and other biogenic amines (Aponte et al., 2010; Pons-Sánchez-Cascado et al., 2005; Yeannes, 1995).

Studies of the microbial dynamics as well as the characteristics of the microorganisms growing in the different stages are of great importance to understand salted fish ripening processes. The knowledge of the microbial ecosystem would contribute to a more efficient control of the process in order to regulate the development of sensorial characteristics. Moreover, it could allow developing a starter culture to accelerate the process or even improve some quality characteristic, as Aponte et al. (2010) have suggested.

The most classical approach for this type of studies is based on cultivable microorganisms, but molecular culture-independent methodologies can be found in more recent microbial communities investigations (Lee et al., 2015; Roh et al., 2009). Even though viable non-culturable microorganisms may be go undetected using traditional microbiological techniques, the benefit of working with cultivable microorganisms is that it permits to get information about the microbial response towards different components or growth conditions by means of phenotypic tests. It is interesting to know the phenotypic response, since bacterial metabolites could be directly related with the sensorial characteristics of this product (Campello, 1985; Czerner and Yeannes, 2014; Gram and Dalgaard, 2002; Hernández-Herrero et al., 1999b; Huss and Valdimarson, 1990). For the analysis of this type of data, multivariate statistical analysis techniques can be used in order to explore variable associations. In this case, variables are of categorical type since the results of the performed biochemical tests have a limited number of possible responses (modalities). For this type of datasets, Multiple
Correspondence Factorial Analysis (MCFA) can be used as an exploratory method that enables to characterize statistical relationships of interdependence between quantitative and qualitative variables and to know how this relationship is structured (Escofier and Pagès, 1998). This multivariate technique is an extension of Correspondence Analysis (CA) and can also be seen as a generalization of Principal Component Analysis (PCA) when the variables to be analyzed are categorical instead of quantitative (Ramette, 2007). MCFA is a useful technique to interpret qualitative high-dimensional data and has been used in different scientific fields. In food investigation, it has been applied, for example, to evaluate sensory properties of wine (Frost et al., 2018), Maillard reaction products (Yu et al., 2012) or risk factors for sheep and goat brucellosis seroprevalence (Coelho et al., 2008).

In this context, the aim of this study was to analyze the main microbial community characteristics during the elaboration process of salted and ripened anchovies (E. anchoita). For this purpose, Multiple Correspondence Factorial Analysis followed by Hierachical Clustering of Principal Component was applied to explore how the manufacturing process stage and the results from phenotypic tests are related. Moreover, it was expected to discern the main characteristics which best describe how the halophilic microbiota could contribute in the process of elaboration of salted and ripened anchovy.

\section{Materials and methods}

\subsection{Production of salted-ripened anchovy and sampling}

Anchovy (Engraulis anchoita) (28-35 pieces per kg) caught during three harvest seasons, near Mar del Plata, Argentina ( $38^{\circ} \mathrm{S}, 5^{\circ} 33^{\prime} \mathrm{W}$ ) and kept in bins with ice until processing, was used as raw material. Three lots of food-grade commercial unwashed semi coarse salt (A, B and $\mathrm{C}$ ) proceeding from a solar saltern located in the province of Rio Negro, Argentina, were used for the salted-ripened anchovy manufacture. Salted-ripened anchovy was produced in a local plant following the standard industrial process.

Fresh whole anchovies were mechanically washed and immediately immersed in saturated brine (proportion brine to fish is not accurately measured in the processing plant, so it can vary in the 1:1/1.3:1 range in the different batches) for a minimum period of $24 \mathrm{~h}$ for pre-salting. Then, fish was manually beheaded and partially gutted (gonads and part of the pyloric caeca remains in the specimen) and disposed in plastic tins $(10 \mathrm{~kg})$, according to the traditional process named "headtail". The tins were packed with alternate layers of fish and salt, finishing with a layer of salt (final salt to fish ratio, 1:5). A plastic disk was placed on the top layer of salt, and weights were put in place in order to maintain the fish under a constant pressure of $80 \mathrm{~kg} / \mathrm{cm}^{2}$. Tins were kept for 395 days in the ripening room. Three independent productions of salted-ripened anchovy were prepared (one for each harvest season); each one consisted of six tins. Salt-ripened anchovies produced were sensorially acceptable, maintaining the typical characteristics of this product.

Samples were aseptically taken from raw materials (salt and fresh anchovies), during brining (wet salting) and during ripening and studied for its microbiological load and bacterial ecosystem. Salt samples $(1 \mathrm{~kg}$ ) were extracted from the different production lots (Salt A, B and C). Fresh anchovy samples $(1 \mathrm{~kg})$ were taken from one batch, immediately before wet salting. Samples of wet salted anchovies $(1 \mathrm{~kg})$ were periodically collected from the bins and from this, 15-20 specimens were manually beheaded and gutted and the fillets analyzed. Samples of $350 \mathrm{~g}$ ( $\sim 15-20$ anchovies) were taken along the ripening process from three different tins selected at random; i.e., 45-60 anchovies $(\sim 1 \mathrm{~kg})$ were sampled for each batch at each sampling time. For sample extraction, the two superior layers of fish were discarded (Czerner and Yeannes, 2014).

All samples were immediately analyzed for their microbiological load in duplicate. 


\subsection{Microbiological analyses}

\subsubsection{Counting, selection and isolation of colonies}

For all cases, two independent $10^{-1}$ homogenates were obtained by homogenizing $10 \mathrm{~g}$ of sample with $90 \mathrm{~mL}$ of sterile salt broth (meat extract, $3 \mathrm{~g} / \mathrm{L}$; meat peptone, $5 \mathrm{~g} / \mathrm{L}$; NaCl, $150 \mathrm{~g} / \mathrm{L}$; ICMSF, 1983). The homogenates were incubated at $35-37^{\circ} \mathrm{C}$ for $30 \mathrm{~min}$ as an enrichment step to recover stressed cells. Following this, decimal dilutions $\left(10^{-2}\right.$ and $10^{-3}$ ) were prepared with salt broth and spread into the growth media in duplicate. The growth media was the complex Sehgal and Gibbons (1960) medium $\left(\mathrm{MgSO}_{4} .7 \mathrm{H}_{2} \mathrm{O}, 20 \mathrm{~g} / \mathrm{L} ; \mathrm{KCl}, 2 \mathrm{~g} / \mathrm{L}\right.$; trisodium citrate, $3 \mathrm{~g} / \mathrm{L}$; yeast extract, $10 \mathrm{~g} / \mathrm{L}$; casein hydrolyzate, $7.5 \mathrm{~g} / \mathrm{L}$; agar, $20 \mathrm{~g} / \mathrm{L} ; \mathrm{Fe}^{2+}, 10 \mathrm{ppm} ; \mathrm{Mn}^{2+}, 0.1 \mathrm{ppm}$ ) with 150 and $200 \mathrm{~g} / \mathrm{L}$ of salt (named G15 and G20, respectively) and was used for halophilic populations monitoring. Plates were incubated at $35-37^{\circ} \mathrm{C}$ during 21 days.

Counts were carried out and the colonies that showed different morphotype (color, size, density and shape) were selected; picked up and re-streaked on fresh G15 and G20. Plates were incubated at $35-37^{\circ} \mathrm{C}$ to obtain pure isolates, which were then transferred to Gibbons broth $\left(\mathrm{MgSO}_{4} .7 \mathrm{H}_{2} \mathrm{O}, 20 \mathrm{~g} / \mathrm{L} ; \mathrm{KCl}, 2 \mathrm{~g} / \mathrm{L}\right.$; trisodium citrate, $3 \mathrm{~g} /$ $\mathrm{L}$; yeast extract, $10 \mathrm{~g} / \mathrm{L}$; casein hydrolysate, $7.5 \mathrm{~g} / \mathrm{L} ; \mathrm{Fe}^{2+}, 10 \mathrm{ppm}$; $\mathrm{Mn}^{2+}, 0.1 \mathrm{ppm}$ ) supplemented with 150 or $200 \mathrm{~g} / \mathrm{L} \mathrm{NaCl}$ to obtain G15 and G20 broth, respectively, and stored at $4{ }^{\circ} \mathrm{C}$ for further analyses.

\subsubsection{Macroscopic and microscopic characterization of isolated microorganisms}

Colony appearance was evaluated through the following macroscopic characteristics: pigmentation, margin and optical properties of the surface (glistening or dull) and through the colony (opaque, translucent or transparent).

The microscopic characterization of the cell morphology of the isolates was carried out on the basis of the Gram staining (optic microscope) (Mc Faddin, 1980).

\subsubsection{Study of salt requirement for the growth of isolated microorganisms}

To determine the growth salinity range of the isolates, complex Sehgal and Gibbons media with increasing levels of $\mathrm{NaCl}(0,1,5,7.5$, 10,15 and $20 \% w / v$ ) were used (ICMSF, 1983). The inoculums were incubated at $35-37^{\circ} \mathrm{C}$. The positive result was indicated by growing. Analyses were carried out in duplicate.

\subsubsection{Biochemical tests of isolated microorganisms}

Cultures were submitted to the following biochemical tests for its characterization: cytochrome oxidase activity by spotting a loopful of culture on a disk impregnated with tetramethyl-p-phenylenediamine oxalate (Oxoid), catalase reaction $\left(\mathrm{H}_{2} \mathrm{O}_{2}, 3 \% \mathrm{v} / \mathrm{v}\right)$, motility, nitrate reduction, citrate utilization on Simmons citrate agar (Britania), inoculation in OF medium (Merck, Darmstadt, Germany) to determine the ability to oxidize and/or ferment glucose and carbohydrate fermentation test for Glucose, Lactose, Sucrose (Mc Faddin, 1980).

In addition, phenotypic tests were carried out in order to determinate those microbial characteristics which could exert an influence on the ripening process. Isolates were analyzed for their $\mathrm{H}_{2} \mathrm{~S}$ and indole production capacities and for their proteolytic and lipolytic activities. Hydrogen sulfide $\left(\mathrm{H}_{2} \mathrm{~S}\right)$ production was tested by inoculation in TSI medium (Britania) which allows the investigation of the production of $\mathrm{H}_{2} \mathrm{~S}$ and also the production of acid and gas from glucose, lactose and sucrose. Indole production was studied by the method of Mc Faddin (1980), through the use of peptone broth and Kovacs's reagent. Proteolytic activity was determined by streaking pure culture in skim milk agar (yeast extract, $3 \mathrm{~g} / \mathrm{L}$; meat peptone, $5 \mathrm{~g} / \mathrm{L}$; agar, $15 \mathrm{~g} / \mathrm{L}$; milk, $10 \mathrm{~mL} / \mathrm{L}$ ) (FIL IDF 73,1974$)$. The plates were incubated at $35-37^{\circ} \mathrm{C}$ for 10 days. Clear zones around the streaks were regarded as positive reactions. Lipolytic activity was studied in a solid medium containing tributyrin and the inoculated plates were incubated at $35-37^{\circ} \mathrm{C}$ for 10 days. The positive reaction was indicated by clear zones around the colonies (FIL IDF 73, 1974).

The culture media used for biochemical tests were supplemented with $\mathrm{NaCl}$ to a final concentration of 150 or $200 \mathrm{~g} / \mathrm{L}$, depending on the media from which the isolate was obtained (G15 or G20), and also with $\mathrm{K}^{+}(10 \mathrm{ppm})$ and $\mathrm{Mg}^{2+}(0.1 \mathrm{ppm})$ in order to provide the specific nutrients needed by halophilic bacteria. All analyses were carried out in duplicate.

\subsection{Statistical analysis}

The results of the colony and cell morphologies, salinity range of growing and biochemical tests were included in the data set for statistical analysis. A total of 28 variables were analyzed. The data table was organized to have a single column for each test and the rows were comprised of each isolate.

Univariate analysis (frequency distribution) was carried out to explore the pattern of response of each variable. The relationship between variables was explored by bivariate analyses, performed using contingency tables and their corresponding independence tests (Chi-square test).

Multiple Correspondence Factor Analysis (MCFA) was used to explore the associations between microbial characterization (biochemical tests) of the isolates and the elaboration process stage (isolation source). Explanatory variables to be included on the MCFA were selected by the Chi-square statistic, using a stepwise method $\left(\mathrm{p}^{<0.05}\right)$. To conduct MCFA, the multidimensional contingency table (Burt matrix) was constructed and analyzed of all two-way cross tabulations across all variables. MCFA decomposes the Burt matrix to find the pairwise associations which account for the greatest proportion of inertia (variance) and displays them on a reduced number of dimensions. Data are represented in a system of coordinated axes and these axes represent the most important dimensions according to the inertia they explain. Graphically, the observations are represented by points and the proximity between them is related to the level of association of the modalities corresponding to the variables assessed. For this analysis, isolation source (salt/fresh anchovy/brining/ripening) was set as supplementary variable.

The MCFA was followed by a Cluster Analysis in order to group the observations. Hierarchical Clustering on Principal Components (HCPC) was applied and the isolates were classified according to common and non-common characteristics. The method used to measure distances was K-Means. Statistical tests were used to measure the specificity of the class (cluster) and the homogeneity through the proportion of each modality (response for each variable) in the class (Cla/Mod) and the proportion of each class in the modality (Mod/Cla), respectively. The criterion to state the variables that describe each group was both $\mathrm{Cla}$ / Mod and Mod/Cla larger than 50\% (Escofier and Pagès, 1998; Ugarte et al., 2008).

For all statistical analyses, the R language (R Core Team, 2014) was used.

\section{Results and discussion}

\subsection{Microbiological counting}

The results of microbiological counts for the different samples analyzed are shown in Table 1 . The colonies presented different external characteristics depending on the type of sample (salt or fish) and also on the process stage (brining or ripening).

In salts A and B, circular colonies colored in shades of reddish/orange (diameter $=1-3 \mathrm{~mm}$ ) predominated, followed by fried egg shaped colonies in beige tonality (size $=4-6 \mathrm{~mm}$ ) and a small number of circular beige creamy colonies (diameter $=1-2 \mathrm{~mm}$ ). In salt $\mathrm{C}$, creamy colonies (diameter $=1-2 \mathrm{~mm}$ ) developed and a few small orange colonies (diameter $\leq 1 \mathrm{~mm}$ ) were also detected. The average microbial counts in salt samples was about $10^{3} \mathrm{cfu} / \mathrm{g}$, with a diversity of 7,10 and 
Table 1

Halophilic microbial counts and number of isolates from salt, fresh anchovy samples, brining and ripening stages.

\begin{tabular}{|c|c|c|c|}
\hline & $\begin{array}{l}\text { Counts in G15 } \\
\log (\mathrm{cfu} / \mathrm{g})\end{array}$ & $\begin{array}{l}\text { Counts in G20 } \\
\log (\mathrm{cfu} / \mathrm{g})\end{array}$ & Number of isolates (total) \\
\hline \multicolumn{4}{|l|}{ Salt } \\
\hline A & $3.32 \pm 0.05$ & $3.56 \pm 0.02$ & 22 \\
\hline B & $3.53 \pm 0.02$ & $3.71 \pm 0.05$ & \\
\hline $\mathrm{C}$ & $3.45 \pm 0.06$ & $3.62 \pm 0.03$ & \\
\hline Fresh anchovies & ND & ND & - \\
\hline \multicolumn{4}{|l|}{ Brining (h) } \\
\hline 0.5 & $4.63 \pm 0.01$ & $5.11 \pm 0.01$ & 30 \\
\hline 1.5 & $5.35 \pm 0.02$ & $5.63 \pm 0.02$ & \\
\hline 2.5 & $6.08 \pm 0.02$ & $5.99 \pm 0.02$ & \\
\hline 3.5 & $5.71 \pm 0.02$ & $5.76 \pm 0.02$ & \\
\hline 5 & $4.31 \pm 0.02$ & $4.45 \pm 0.02$ & \\
\hline 8 & $4.11 \pm 0.05$ & $4.87 \pm 0.05$ & \\
\hline 10 & $4.32 \pm 0.08$ & $4.69 \pm 0.08$ & \\
\hline 12 & $4.25 \pm 0.02$ & $4.45 \pm 0.02$ & \\
\hline 24 & $4.27 \pm 0.01$ & $4.34 \pm 0.01$ & \\
\hline 30 & $4.13 \pm 0.05$ & $4.34 \pm 0.05$ & \\
\hline \multicolumn{4}{|l|}{ Ripening } \\
\hline \multicolumn{4}{|l|}{ 1st part (days) } \\
\hline 4 & ND & ND & 12 \\
\hline 10 & $\mathrm{ND}$ & ND & \\
\hline 34 & $4.18 \pm 0.09$ & ND & \\
\hline 69 & $3.97 \pm 0.17$ & ND & \\
\hline 73 & $4.08 \pm 0.15$ & ND & \\
\hline 98 & $4.03 \pm 0.15$ & ND & \\
\hline \multicolumn{4}{|l|}{ 2nd part (days) } \\
\hline 127 & $4.38 \pm 0.34$ & $4.6 \pm 0.11$ & 15 \\
\hline 134 & $4.14 \pm 0.12$ & $3.30 \pm 0.09$ & \\
\hline 198 & $4.38 \pm 0.15$ & $4.41 \pm 0.10$ & \\
\hline 255 & $4.48 \pm 0.34$ & $4.41 \pm 0.12$ & \\
\hline
\end{tabular}

ND (non detected) corresponds to counts $<10 \mathrm{cfu} / \mathrm{g}$.

5 colonies having different morphotypes in salts $\mathrm{A}, \mathrm{B}$ and $\mathrm{C}$, respectively.

In fresh anchovies, no halophilic microorganisms presence was detected in complex Sehgal and Gibbons medium with different salt content (G15 and G20) ( ${ }^{<} 10 \mathrm{cfu} / \mathrm{g}$ ). This is in accordance with other studies showing that the halophilic bacteria incidence in anchovies is low at this salinity range (Perez et al., 2017).

During the brining stage, the majority of the colonies showed similar morphological characteristics, prevailing beige creamy colonies (diameter $=1-3 \mathrm{~mm}$ ). Colonies colored in shades of reddish/orange (diameter $=1-2 \mathrm{~mm}$ ) were also noticed. Along this stage, a total of 30 colonies with different morphology were isolated. The time of brining directly affected the halophilic microbial counts. A sharp increase was observed during the first $2.5 \mathrm{~h}$. This change should be directly related to the initial concentration of microorganisms in the brine which is prepared before the fish is immersed. In this period halophilic microorganisms (from salt) could develop in a certain extent prior to be in contact with anchovies and the change in the counts would be given by the contact of the fish with the brine. A decreasing tendency until a stable value of $\sim 10^{4} \mathrm{cfu} / \mathrm{g}$ was reached after $5 \mathrm{~h}$ of brining. Even though it is possible to observe that counts in G20 are larger than those determined in G15, the difference is less than one logarithmic cycle for all sampling times in this isolation source.

Regarding the ripening stage, no halophilic bacteria were detected during the first month $(<10 \mathrm{cfu} / \mathrm{g})$. Starting from the second month of ripening, bacterial growth was detected in G15. Small (diameter $=1-2 \mathrm{~mm}$ ) bright orange colonies with translucent appearance and colonies colored in shades of brown and larger than the previous ones were developed. White, flat surface, and smooth colonies were also noticed growing in this medium. Counts of halophilic bacteria in G20 were detected from the fifth month to the end of the process showing less diversity of colonies than the previous observed period, with a prevalence of small, pink and coral colored ones.

The microbiological counts during ripening can be explained by the abrupt modification of the growing conditions that takes place when fish is packed in barrels. In barrels, alternate layers of anchovies and salt are placed and kept pressed to promote water and fat expulsion from fish tissue as well as to help to dislodge the occluded air. The top of the barrel remains covered by the brine solution formed with the drained out water and the added salt. Thus, the environment for microbiological development changes from aerophilic (brining) to microaerophilic (barrels), added to the increase in the $\mathrm{NaCl}$ content up to values $14-18 \% \mathrm{w} / \mathrm{w}$ and the $\mathrm{a}_{\mathrm{w}}$ reduced to $\sim 0.75$ (Czerner and Yeannes, 2014). This modification would contribute to stress and reduce the halophilic flora, explaining the lack of microbial counts during the first month of ripening. Once microbiota is adapted to the new environmental conditions, it is able to grow again. Interestingly, counts obtained after the first month of ripening are in the same order as those determined at the end of brining.

Colonies growing at $15 \% \mathrm{NaCl}$ (G15) would belong to moderate halophilic bacteria and colonies isolated in culture media with $20 \%$ $\mathrm{NaCl}$ (G20) would correspond to extreme halophilic bacteria on the basis of their salt tolerance, pigmentation and morphology (Holt, 1989). It must be taken into account that a fraction of the colonies counted in G15 and G20 might be the same strain because actually halophilic bacteria grow in a certain range of salt content.

For statistical analysis, salt samples were identified as IS1 and samples collected during the stage of brining, IS2. The results of samples from ripening were divided into two stages: from $t=0$ until the fourth month inclusive (IS3) and from the fifth month onwards (IS4), considering for this division the time from which microbial growth is detected in G20 (see Table 1). Fresh anchovy was omitted from this analysis since no halophilic colonies were isolated from this source.

\subsection{Statistical analysis}

A description of the categorical variables and the obtained results are shown in Table 2.

\subsubsection{Univariate and bivariate analyses}

Table 2 shows the results of the univariate (frequency distribution of responses) and bivariate analyses performed. Bivariate analyses were conducted between isolation source and the other observed variables in order to explore possible relationships between bacterial population characteristics and IS1, IS2, IS3 and IS4. In addition, the relationship between variables with technological interest was explored. Considering that red halophiles are generally assumed as the responsible of salted fish products spoilage, it was interesting to analyze if the colony pigmentation had a relationship with those activities that could lead to off-flavors development (lipolysis, proteolysis, indole and $\mathrm{H}_{2} \mathrm{~S}$ production) (Gram and Huss, 1996; Huss and Valdimarson, 1990). Catalase and oxidase tests were included in this analysis based on their proved implications in the improvement of color stability and the decrease of rancidity development in fermented meat product (Geisen et al., 1992). Thus, two additional bivariate analyses sets were carried out. The first one, between pigmentation and the following variables: proteolysis, lipolysis, indole, $\mathrm{H}_{2} \mathrm{~S}$, oxidase and catalase. The second one, between proteolysis and lipolysis. The results obtained in each case for the independent test are given in Table 2. Figs. 1, 2 and 3 show the results obtained for those cases in which the variables resulted associated $(\mathrm{p}<0.05)$.

Among the macroscopic variables determined in this investigation, only light transmitted through the colony was related with isolation source (Table 2, Fig. 1a). Salt samples showed more diversity on this characteristic. These data are of special interest because isolates were selected based on colony appearance and this property affects the naked eye biodiversity observed in plates. On the other hand, isolates pigmented in shades of reddish/orange were $59 \%$ of the total and resulted 
Table 2

Results of univariate and bivariate analysis.

\begin{tabular}{|c|c|c|c|c|c|c|}
\hline & \multirow[t]{2}{*}{ Variables } & \multirow[t]{2}{*}{ Categories } & \multirow{2}{*}{$\begin{array}{l}\text { Frequency } \\
\text { distribution } \\
(\%)\end{array}$} & \multicolumn{3}{|c|}{ Independence test ( $p$ value) } \\
\hline & & & & $\begin{array}{l}\text { Isolation } \\
\text { source }\end{array}$ & Pigmentation & Proteolysis \\
\hline \multirow[t]{4}{*}{ Isolation } & \multirow[t]{4}{*}{ Isolation source } & Salt samples (IS1) & 28 & \multirow[t]{4}{*}{1.000} & \multirow[t]{4}{*}{-} & \multirow[t]{4}{*}{-} \\
\hline & & Brining stage (IS2) & 38 & & & \\
\hline & & $\begin{array}{l}\text { Ripening until 4th month } \\
\text { (IS3) }\end{array}$ & 15 & & & \\
\hline & & $\begin{array}{l}\text { Ripening from 5th month } \\
\text { (IS4) }\end{array}$ & 19 & & & \\
\hline \multirow[t]{9}{*}{ Colony appearance } & \multirow[t]{2}{*}{ Pigmentation (reddish/orange) } & Negative & 41 & \multirow[t]{2}{*}{0.067} & \multirow[t]{2}{*}{1.000} & - \\
\hline & & Positive & 59 & & & \\
\hline & Margin & Regular & 78 & 0.734 & - & - \\
\hline & & Irregular & 22 & & & \\
\hline & Optical properties of surface & Dull & 11 & 1.000 & - & - \\
\hline & & Glistening & 89 & & & \\
\hline & Optical properties through colony & Translucent/transparent & 28 & 0.045 & - & - \\
\hline & & Opaque & 68 & & & \\
\hline & & Mixed & 4 & & & \\
\hline Microscopic characterization & Gram staining & Negative & 77 & 0.012 & - & - \\
\hline & & Positive & 23 & & & \\
\hline & Morphology & Rod-shaped & 37 & 0.000 & - & - \\
\hline & & Coccoid & 53 & & & \\
\hline & & Short oval rod & 4 & & & \\
\hline & & Disc-shaped & 6 & & & \\
\hline Salt requirement & 0 & Negative & 91 & 0.593 & - & - \\
\hline$(\% \mathrm{w} / \mathrm{v})$ & & Positive & 9 & & & \\
\hline & 1 & Negative & 57 & 0.000 & - & - \\
\hline & & Positive & 43 & & & \\
\hline & 5 & Negative & 42 & 0.000 & - & - \\
\hline & & Positive & 58 & & & \\
\hline & 7.5 & Negative & 22 & 0.000 & - & - \\
\hline & & Positive & 78 & & & \\
\hline & 10 & Negative & 18 & 0.003 & - & - \\
\hline & & Positive & 82 & & & \\
\hline & 15 & Negative & 0 & 0.605 & - & - \\
\hline & & Positive & 100 & & & \\
\hline & 20 & Negative & 4 & 0.034 & - & - \\
\hline & & Positive & 96 & & & \\
\hline Biochemical tests & Cytochrome oxidase activity & Negative & 8 & 0.452 & 0.310 & - \\
\hline & & Positive & 92 & & & \\
\hline & Catalase reaction & Negative & 10 & 0.693 & 0.232 & - \\
\hline & & Positive & 90 & & & \\
\hline & Motility & Negative & 48 & 0.053 & - & - \\
\hline & & Positive & 53 & & & \\
\hline & Nitrate reduction & Negative & 28 & 0.194 & - & - \\
\hline & & Positive & 72 & & & \\
\hline & Citrate utilization on Simmons citrate agar & Negative & 85 & 0.016 & - & - \\
\hline & & Positive & 15 & & & \\
\hline & Acid production from Glu fermentation & Negative & 71 & 0.000 & - & - \\
\hline & & Positive & 29 & & & \\
\hline & Acid production from Lac fermentation & Negative & 91 & 0.031 & - & - \\
\hline & & Positive & 9 & & & \\
\hline & Acid production from Suc & Negative & 75 & 0.000 & - & - \\
\hline & & Positive & 25 & & & \\
\hline & Indole production capacity & Negative & 47 & 0.001 & 0.210 & - \\
\hline & & Positive & 53 & & & \\
\hline & Proteolytic activity & Negative & 74 & 0.452 & 0.003 & 1.000 \\
\hline & & Positive & 26 & & & \\
\hline & Lipolytic activity & Negative & 59 & 0.641 & 0.069 & 0.000 \\
\hline & & Positive & 41 & & & \\
\hline & $\mathrm{H}_{2} \mathrm{~S}$ production capacity (TSI medium) & Negative & 74 & 0.000 & 0.051 & - \\
\hline & & Positive & 26 & & & \\
\hline & Production of acid and gas from Glu, Lac and & Non-sugars fermented & 65 & 0.000 & - & - \\
\hline & Suc (TSI medium) & Glu fermented & 1 & & & \\
\hline & & $\begin{array}{l}\text { Glu, Lac and/or Suc } \\
\text { fermented }\end{array}$ & 34 & & & \\
\hline & Glu oxidation and/or fermentation ability (OF & Without changes & 29 & 0.000 & - & - \\
\hline & medium) & Oxidative & 18 & & & \\
\hline & & Fermentative & 53 & & & \\
\hline
\end{tabular}

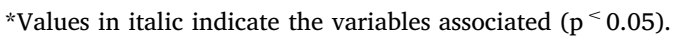

Glu: glucose, Suc: sucrose, Lac: lactose. 

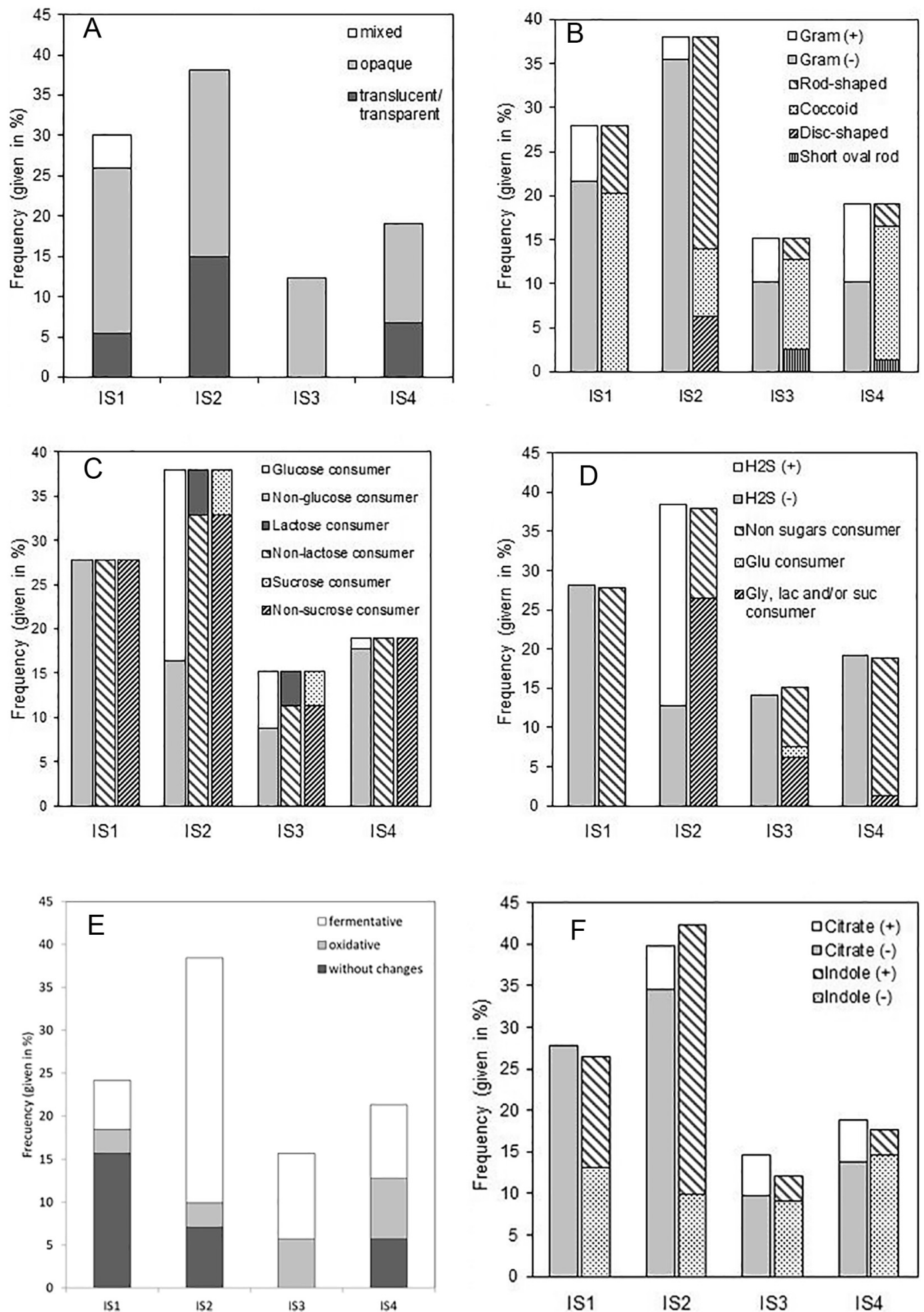

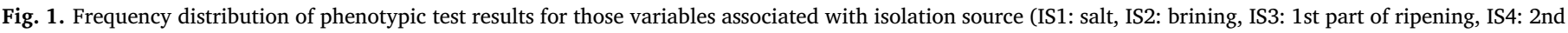
part of ripening) in the bivariate analysis ( $p<0.05$ ). a) Colony morphology; b) Cell morphology; c) Sugars consumption; d) TSI; e) OF; f) Indole and citrate.

independent of the isolation source. As mentioned in the Introduction Section, its importance lies in that red halophiles are associated with spoilage. Extreme halophilic red bacteria are responsible for the formation of a reddish silt of the surface of salty marine products, known as "pink" condition, producing off-odors and flavors related to deterioration (Gram and Huss, 1996). The results of this study indicate that pigmented and non pigmented isolates are uniformly distributed over the different isolation sources, meaning that red halophiles are not particularly developed in a specific process stage.

Regarding to microscopic observations, isolates were mainly cocci, followed by rod-shaped cells; being the majority of them Gram negative. Both characteristics were related with the origin of the isolates (Table 2). As can be seen in Fig. 1b, disc-shaped cells appeared only during brining whereas short oval rods were observed only during ripening. Moreover, the main difference found with Gram staining is that positive isolates appeared in a higher ratio during the second part of 


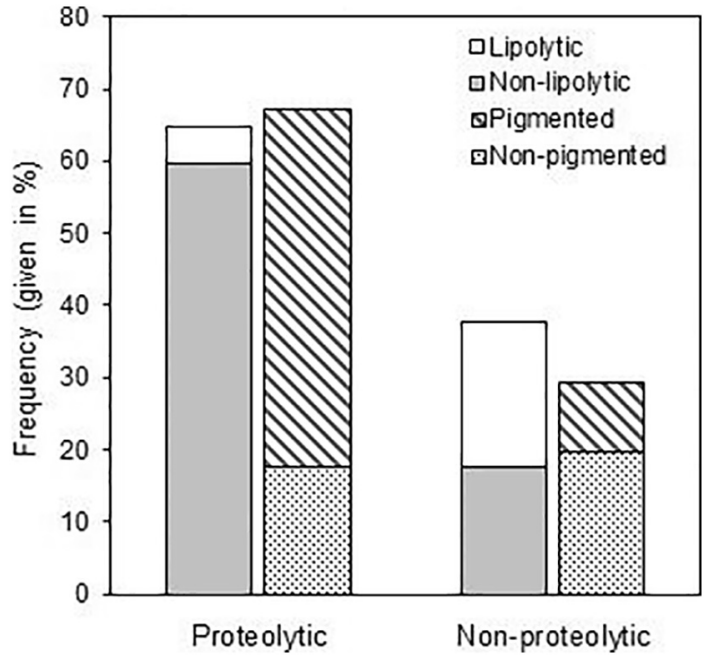

Fig. 2. Frequency distribution of phenotypic test results for variables associated with the proteolytic capacity in the bivariate analysis $(p<0.05)$.

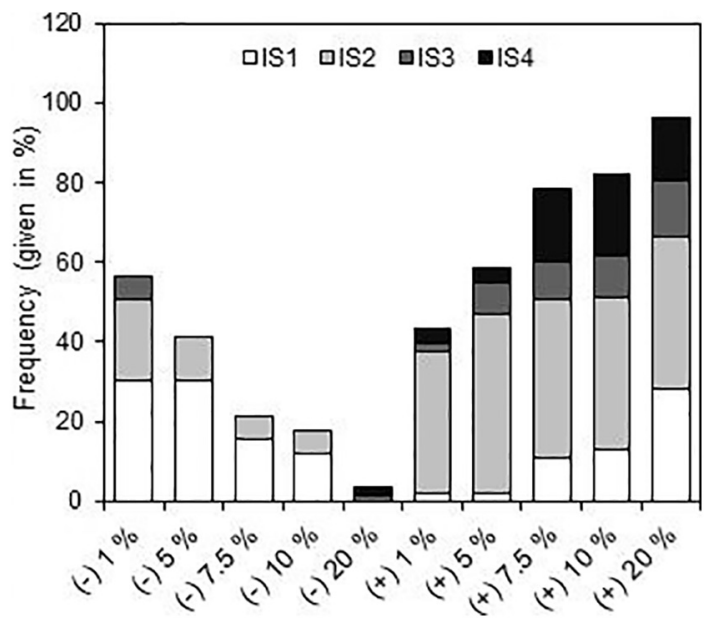

Fig. 3. Frequency distribution of the responses towards salt tolerance/requirement for the isolates proceeding from the different isolation sources (IS1: salt, IS2: brining, IS3: 1st part of ripening, IS4: 2nd part of ripening). Note: The values reported correspond to the percentage of growing isolates at each salt level. Results for salt requirement include missing data. The percentage of isolates analyzed for each $\mathrm{NaCl}$ concentration is as follows: $1 \% w / v, 67 \% ; 5 \%$ $\mathrm{w} / \mathrm{v}, 67 \% ; 7.5 \% \mathrm{w} / \mathrm{v}, 82 \% ; 10 \% \mathrm{w} / \mathrm{v}, 86 \% ; 20 \% \mathrm{w} / \mathrm{v}, 99 \%$.

ripening and in lower proportion during brining and in salt samples.

Focused on biochemical test, the majority of the isolates presented cytochrome oxidase activity and positive catalase reaction and resulted independent from the isolation source (Table 2). Even though there are not investigations relating these capacities with sensory quality of fermented fish, these could be desirable capacities considering that has been stated as important functional properties of the main bacterial starter cultures for meat fermentation. The enzyme catalase catalyzes the decomposition of hydrogen peroxide, a reactive form of oxygen implicated in unsaturated fatty acids oxidations. Moreover, cytochrome oxidase activity would contribute to reduce the oxygen present in the sinus of the barrel and thus avoid rancidity due to an excess of aldehydes from fatty acid oxidation (Talon and Leroy, 2014).

Other biochemical characteristics tested were sugars, nitrate and citrate utilization and motility. Motility and nitrate tests resulted independent from the isolation source, while citrate utilization and sugars utilization were strongly related with the isolate origin. The individual sugars tests in liquid medium showed that the majority of the isolates were non-glucose, non-lactose and non-sucrose consumers. However, a higher percentage of sugars utilization was determined on TSI agar (Table 2). This difference can be explained by the different composition of each culture medium. Regarding to glucose oxidation and/or fermentation ability (OF medium), there was an increase on the positive results compared to TSI test and glucose consumption test. This fact can be attributed to the high percentage of isolates with fermentative metabolism (anaerobic) (Fig. 1e). Regarding the dependence of sugars utilization on isolation source (Fig. 1c, d and e), the higher quantity of sugars consumers are grouped in isolates from the brining stage, secondly from the first part of ripening followed by the second part of ripening. On the other hand, non-sugars consumers were detected from salt through individual sugars tests or TSI medium whereas a low ratio of isolates capable to oxidize and ferment glucose was determined in OF. As seen in Fig. 1f, the main difference about citrate utilization is that there were not detected positive results from salt isolates. All these tests do not have a direct relationship with the characteristics of the process, but contribute to the general study of the characteristics of biodiversity.

Among the biochemical characteristics that could be directly related with the process, indole production and lipolytic activity presented the larger positive results (about 40-50\%) and isolates with $\mathrm{H}_{2} \mathrm{~S}$ production and proteolytic capacities were about $25 \%$. Proteolytic and lipolytic activities showed to be equilibrated along the process and resulted to be independent from the isolation source. Regarding indole and $\mathrm{H}_{2} \mathrm{~S}$ production, they were strongly related with isolate origin (Table 2). As can be seen in Fig. $1 \mathrm{~d}$ and $\mathrm{f}, \mathrm{H}_{2} \mathrm{~S}$ producers were only found during brining and indole producers mainly in salt and brining samples. These results are of great interest because of its implication on off-flavors development and spoilage of salted fish products (Huss and Valdimarson, 1990). The balanced distribution of proteolytic and lipolytic isolates during all the process is desirable due to their contribution to the development of texture and final aroma, respectively. Even though the contribution of bacteria to the mechanism of proteolysis in salted fish has not been studied in detail, the results obtained in this investigation and those reported by Czerner and Yeannes (2014) are consistent with a collaborative role of endogenous enzymes and bacterial enzymes in the process, the former preparing peptide substrates for the later (Hugas and Monfort, 1997). In the same way, bacterial lipolysis would contribute to the release of free fatty acids during ripening which are directly related with flavor development (Triqui and Reineccius, 1995). An excess of any of these activities during a certain stage of the process could lead to quality loss or spoilage (Czerner and Yeannes, 2014).

On the other hand, the independence test showed that proteolytic activity vs pigmentation $(p=0.003)$ and proteolytic vs lipolytic activities $(p=0.000)$ were strongly related, while lipolysis, indole, $\mathrm{H}_{2} \mathrm{~S}$, catalase, oxidase and pigmentation were not significant related $(p \geq 0.069)$. The fact that the majority of red halophiles were proteolytic is consistent with literature and is actually one of the causes of salted fish spoilage (Huss and Valdimarson, 1990). Otherwise, as shown in Fig. 2 proteolytic isolates were generally non-lipolytic, which could suggests that the participation of a bacterial consortium is necessary because of different bacteria contribute with dissimilar properties.

The study of salt requirement showed more positive responses when the salt content was progressively increased from 0 to $15 \% \mathrm{w} / v$ with a slight decrement at $20 \% \mathrm{w} / \mathrm{v}$ (Table 2 ). The bivariate test in salt contents of $1,5,7.5,10$ and $20 \% \mathrm{w} / \mathrm{v}$ resulted strongly related to the isolation source. By plotting positive and negative results on the abscissa axis it can be clearly seen that the amount of negative results decrease when salt content increase whereas positive results increases with increasing salt content (Fig. 3). This is expected given the high salt content and low $\mathrm{a}_{\mathrm{w}}$ found in anchovies during the process and the characteristic halophilic microbiota (Czerner and Yeannes, 2014; Felix et al., 2016). When the isolation source is analyzed, the main difference found is that lower quantities of isolates from salt are able to grow in 1, $5,7.5$ and $10 \% \mathrm{w} / \mathrm{v}$, in comparison with those proceeding from the other sources. On the other hand, isolates not capable to grow at $20 \%$ 
$\mathrm{w} / \mathrm{v} \mathrm{NaCl}$ appeared in the second part of the ripening. These results showed that extremely halophilic isolates mostly belonged to salt samples.

\subsubsection{Multiple Correspondence Factorial Analysis and Cluster Analysis}

In order to evaluate potential relationships between variables that would not be discovered in a set of paired comparisons, Multiple Correspondence Factorial Analysis (MCFA) was applied. The objective of this analysis was the investigation of the associations among the results of microbial characterization and the elaboration process stage. Among the analyzed variables, only biochemical tests (14 variables) were included in the MCFA because the interest here was focused on those bacterial characteristics that could be related to the development of the typical characteristics of salted-ripened anchovy or its spoilage. For this reason, colony appearance, microscopic characteristics and salt requirement were excluded from the MCFA.

The variable origin (isolation source) was included and set supplementary for the analysis, i.e. as descriptive but non-qualifying. This type of variables does not contribute to the inertia, but can be projected onto the dimensions after the original analysis on the variables. From the 15 variables analyzed ( 14 corresponding to biochemical test and 1 to isolation source), the following 11 were significant for the model $(p \leq 0.024): \mathrm{H}_{2} \mathrm{~S}$ production capacity and production of acid and gas from glucose, lactose and sucrose (TSI medium); acid production from glucose, lactose and sucrose; glucose oxidation and/or fermentation ability (OF medium); cytochrome oxidase activity; motility; indole production capacity, proteolytic activity and isolation source. After a first analysis, the variables catalase reaction, nitrate reduction, citrate utilization on Simmons citrate agar and lipolytic activity were non significant for the model, so they were not kept in the MCFA as explanatory variables (Escofier and Pagès, 1998).

Throughout the MCFA, $80 \%$ of the inertia was explained with 11 axes. As shown in Fig. 4, the first two components captured $29.8 \%$ of the variability. Also, 95\% confidence ellipses are plotted for each isolation source. Factor map provided a first idea of the position of the individual from each other, showing that the isolates of the salt are far from the other isolates obtained during brining and ripening. It must be considered that confidence ellipses did not include a high percentage of the data when represented in two dimensions because it is needed a higher number of dimensions to fully explain the inertia (not graphible).

Isolates were classified by Hierarchical Clustering on Principal Components (HCPC) (Fig. 5). In the dendogram, it is possible to discern

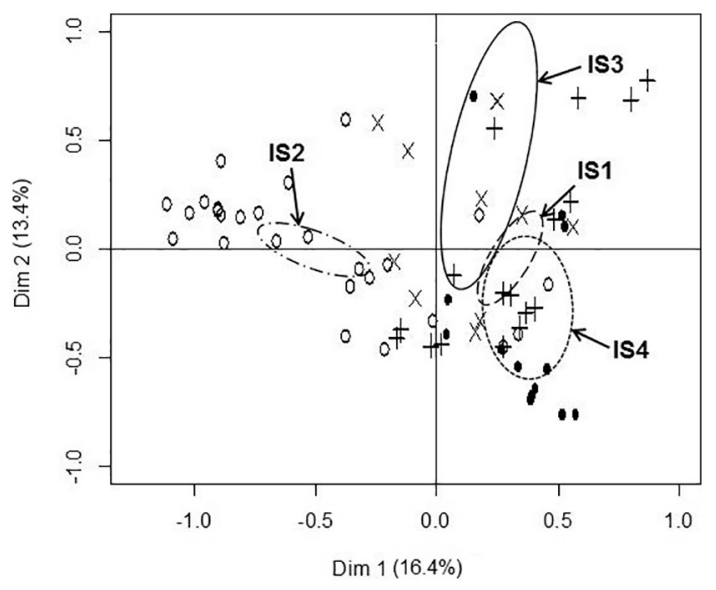

Fig. 4. Correspondence analysis factor map showing the positions of each isolate by biochemical test results along with isolation sources. Legend: + = IS1, salt samples; ${ }^{\circ}=$ IS2, brining stage; $\times=$ IS3: first stage of ripening (until fourth month); $\cdot=$ IS4, second stage of ripening (from fifth month onward). $95 \%$ confidence ellipses are plotted for each isolation source. the conformation of two clusters at a linkage distance 0.175. Each isolation source and cluster combination is exposed within the factor map as a number/shape combination (Fig. 6). Numbers 1 to 22 correspond to isolates from salt (IS1), 23 to 52 from brining (IS2), 53 to 64 from the first part of ripening (IS3) and 65 to 79 from the second part of ripening (IS4). The clusters were well defined if the biochemical characteristics and conformation of the groups are considered. Table 3 includes the information of the variables describing each cluster and the description of the procedence of the isolates that constitute each group. In Table 3, Cla/Mod represents the percentage of isolates that have the modality "i" and belong to the cluster " $\mathrm{j}$ " and Mod/Cla, the percentage of isolates belonging to cluster " $\mathrm{j}$ " that show the modality "i". i.e.: for the first test enumerated in the table, "Production of acid and gas from glucose, lactose and sucrose (TSI medium)", Cla/Mod is the percentage of isolates that are "Glucose, lactose and/or sucrose fermenter (TSI medium)" and belong to the Cluster 1; Mod/Cla is the percentage of isolates belonging to Cluster 1 that are "Glucose, lactose and/or sucrose fermenter (TSI medium)".

Isolates belonging to Cluster 1 are mainly grouped by its ability to produce acid from sugars, being able to ferment glucose under anaerobic conditions. Sugars consumption has not been demonstrated to have implications in the process of elaboration of salted-ripened anchovies, but represents metabolic characteristics of the isolates. Furthermore, it was identified as indole and hydrogen sulfide producer and mainly constituted by mobile bacteria. Interestingly, this group is described as being brining its main isolation source with no presence of isolates from salt or from the 2nd part of brining. Descriptors as $\mathrm{H}_{2} \mathrm{~S}$ and indole production have been stated not desirable for the process as previously mentioned (Huss and Valdimarson, 1990).

The Cluster 2 was described as being non-sugars fermenter (TSI and individual sugars tested in broth), non- $\mathrm{H}_{2} \mathrm{~S}$ producer, non-indole producer, immobile and cytochrome oxidase active. Despite isolation source was not a Cluster 2 descriptor, it is remarkable that this group included all the isolates coming from salt and from the 2nd part of ripening, the $83.3 \%$ of the isolates from the 1 st part of ripening and only $26.7 \%$ from brining. This grouping indicates that the isolates from ripening shows similar biochemical characteristics than those from salt, which could suggest a positive participation in the process since they not presented activities related to spoilage as Cluster 1 did.

The clusters conformation is consistent with the results of microbiological counts (Table 1) in which the diversity presented during brining was sharply reduced in the beginning of ripening to not detected counts $(<10 \mathrm{cfu} / \mathrm{g})$ with a subsequent proliferation of different bacteria with biochemical characteristics similar to that of salt microbiota. This similarity between the characteristics of isolates from salt and from ripening can be observed by the proximity of the isolation sources when are projected in the factor map (Fig. 4). Confidence ellipses corresponding to IS1 and IS4 are well overlapped and IS3 is located very close to the former ones. Conversely, IS2 is clearly discriminated from the other isolation sources. The fact that Cluster 1 includes non-desirable characteristics with isolates proceeding from brining whereas Cluster 2 relates isolates mainly from salt and ripening with some desirable bacterial activities would indicate that the ripening process of salted anchovies favors the natural selection of bacteria beneficial for the development of the typical product sensory attributes. However, more studies are needed to confirm this hypothesis.

It is interesting that no cluster was characterized by proteolytic activity in accordance with the results of the bivariate analysis, which also indicated independence between isolation source and lipolytic activity. As mentioned in Section 3.2.1, it is well known that compounds derived from proteolysis and lipolysis would contribute to the development of the characteristic flavor. Proteolysis contributes to the development of texture (Czerner and Yeannes, 2014; Gram and Huss, 1996) and taste (Steffánson and Guðmundsdóttir, 1995), while lipolysis is more related with the aroma of the product (Triqui and Reineccius, 1995). However, large counts of proteolytic and/or lipolytic bacteria 


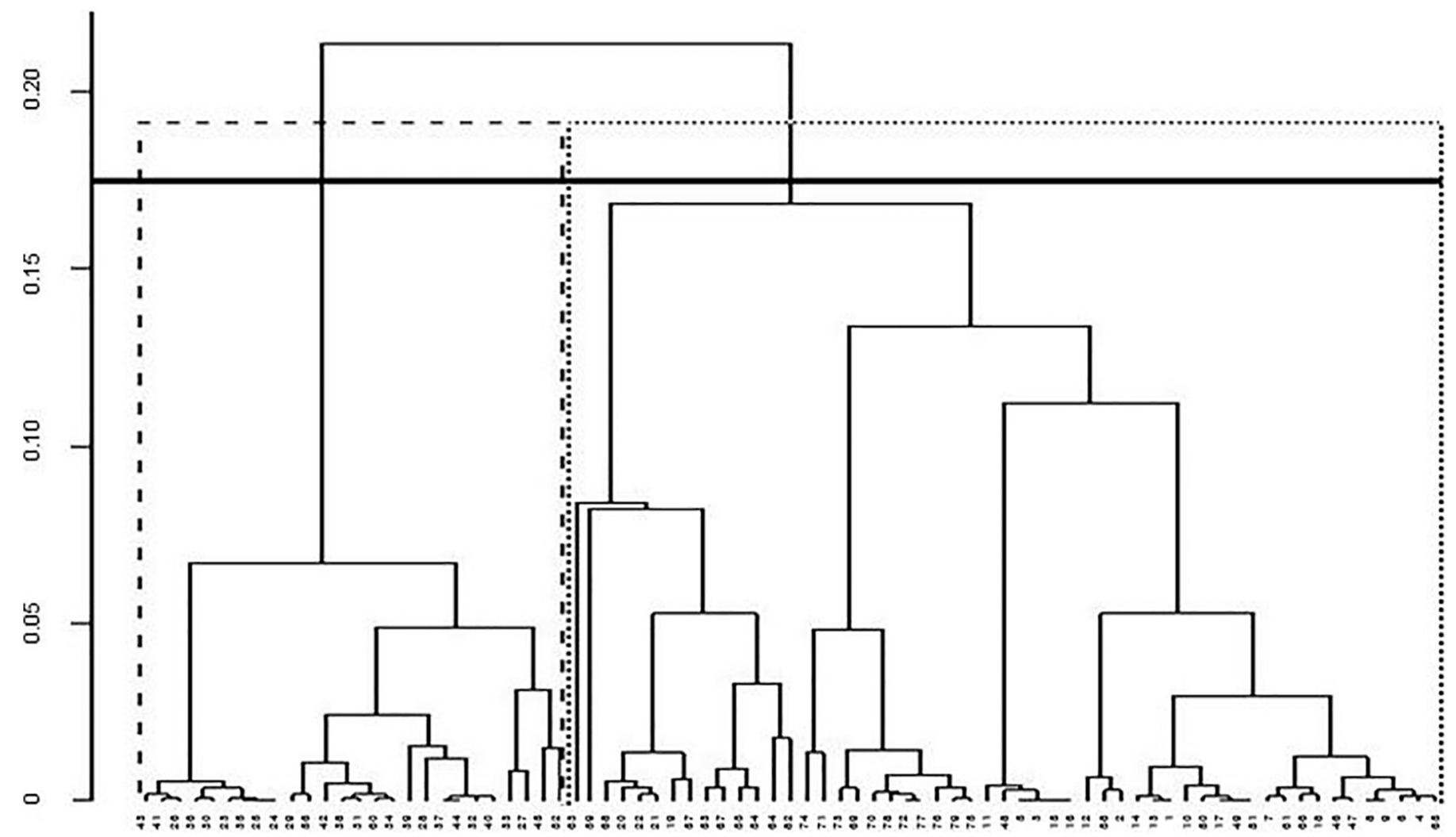

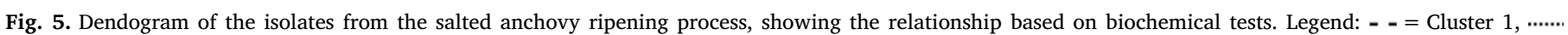
$=$ Cluster 2 .

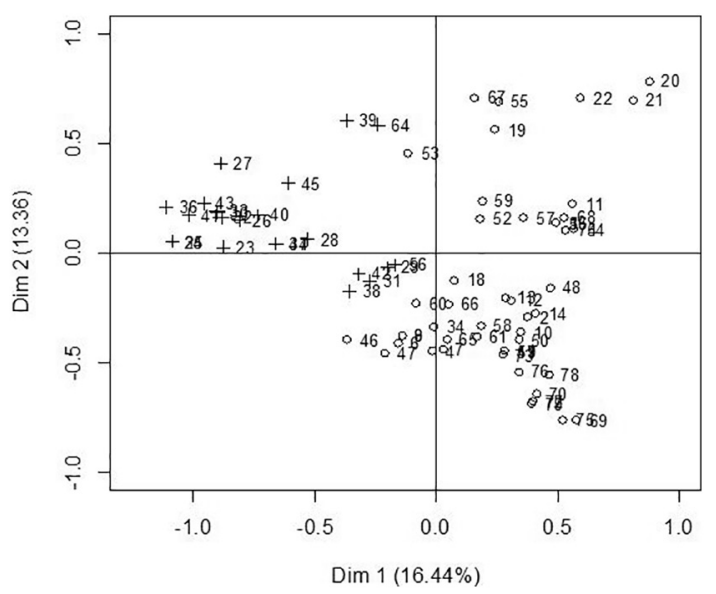

Fig. 6. Correspondence analysis factor map showing the isolates that belong to the different clusters (shape) along with the isolation source (number). Legend: $+=$ Cluster $1 ;^{\circ}=$ Cluster 2 . Numbers 1 to 22 correspond to isolates from salt (IS1), 23 to 52 from brining (IS2), 53 to 64 from the first part of ripening (IS3) and 65 to 79 from the second part of ripening (IS4).

could lead to unbalanced development of sensory characteristics during ripening or to accelerate the end of shelf life by producing of off-flavors. The results obtained in this work would indicate that the influence of microbial proteolytic and lipolytic activities in the development of the characteristic flavor could be continuous during the salting-ripening anchovy process.

\section{Conclusions}

Salting and ripening of anchovies is a complex and dynamic process in which halophilic bacteria predominate. Through Univariate and
Bivariate Analyses it was possible to discern which bacterial phenotypic characteristics predominate in the different process stages, focusing on those with technological interest. An important number of positive results were obtained for indole and $\mathrm{H}_{2} \mathrm{~S}$ production and also for lipolytic and proteolytic activities. It was noticeable that isolates with proteolytic and lipolytic capacities were uniformly isolated along the process; which is a desirable condition due to the positive contribution to the development of texture and final aroma, respectively. Negative microbial characteristics, as $\mathrm{H}_{2} \mathrm{~S}$ or indole production, were mainly found in salt samples and during brining, but not during ripening.

Microbial counts changed during processing but the final values achieved in the ripening and brining stages are in the same magnitude order even though the isolates of each stage presented different external characteristics. This fact suggests that these stages are dominated by different bacterial populations. Moreover, the MCFA of biochemical tests reaffirm this observation showing that isolates from brining and ripening were well discriminated and were classified into two different clusters. In this analysis, those proceeding from brining were associated with non-desirable activities for the process $\left(\mathrm{H}_{2} \mathrm{~S}\right.$ and indole production) which could lead to the development of off-flavors. On the other hand, isolates mainly from salt samples and ripening are included in another cluster, characterized by some desirable bacterial capacities (Cytochrome oxidase activity and non- $\mathrm{H}_{2} \mathrm{~S}$ and non-indole production). The results obtained in this investigation would indicate that during the ripening process of salted anchovies, the bacteria ecosystem is modified and takes place a natural selection of those with capacities that can help the development of the desired sensory attributes. It is known that the stage of brining is critical to inhibit native and contaminant microorganisms that could lead to anchovy spoilage, but the results obtained here also indicate that halophilic bacteria developing during this stage has not desired characteristics to the process neither. Phenotypic characterization of microbiota found during the salting-ripening process could be useful in future investigations in order for example to 
Table 3

Description of the clusters formed by hierachical clustering of principal components, based on biochemical tests.

\begin{tabular}{|c|c|c|c|c|}
\hline Cluster & $\begin{array}{l}\text { Cluster characterization } \\
\text { (Decreasing order of Cla/Mod Mod/Cla) }\end{array}$ & $\begin{array}{l}\text { Cluster } \\
\text { frecuency }\end{array}$ & $\begin{array}{l}\text { Isolate percentage (\%) on the total of each } \\
\text { isolation source } \\
\text { (percentage:source) }\end{array}$ & $\begin{array}{l}\text { Cluster constitution (\%) according to isolate source } \\
\text { (percentage:source) }\end{array}$ \\
\hline 1 & $\begin{array}{l}\text { - Glu, Lac and/or Suc fermenter (TSI } \\
\text { medium) } \\
\text { - Suc fermenter (tested in broth) } \\
\text { - Isolation source: brining stage (IS2) } \\
\text { - } \mathrm{H}_{2} \mathrm{~S} \text { producer (TSI medium) } \\
\text { - Glu fermenter (tested in broth) } \\
\text { - Indole producer } \\
\text { - Fermentative Glu metabolism (anaerobic } \\
\text { in OF medium) } \\
\text { - Mobile }\end{array}$ & 24 & $\begin{array}{l}73.3 \% \text { : brining } \\
16.7 \% \text { : ripening (1st part) }\end{array}$ & $\begin{array}{l}\text { 91.7\%: brining } \\
\text { 8.3\%: ripening (1st part) }\end{array}$ \\
\hline 2 & $\begin{array}{l}\text { - Non-sugars fermenter (TSI medium) } \\
\text { - Non- } \mathrm{H}_{2} \mathrm{~S} \text { producer (TSI medium) } \\
\text { - Non-Glu fermenter (tested in broth) } \\
\text { - Immobile } \\
\text { - Non-indole producer } \\
\text { - Non-Suc fermenter (tested in broth) } \\
\text { - Non-Lac fermenter (tested in broth) } \\
\text { - Cytochrome oxidase activity }\end{array}$ & 55 & $\begin{array}{l}\text { 100\%: salt } \\
26.7 \% \text { : brining } \\
83.3 \% \text { : ripening (1st part) } \\
100 \% \text { : ripening (2nd part) }\end{array}$ & $\begin{array}{l}\text { 40.0\%: salt } \\
14.5 \% \text { : brining } \\
18.2 \% \text { : ripening (1st part) } \\
27.3 \% \text { : ripening (2nd part) }\end{array}$ \\
\hline
\end{tabular}

Cla/Mod: The percentage of isolates that have the modality "i” and belong to the cluster "j"; Mod/Cla: The percentage of isolates belonging to cluster "j" that show the modality "i". Glu: glucose, Suc: sucrose, Lac: lactose.

select starter cultures.

\section{Acknowledgements}

The authors would like to thanks Ms. Irene Ameztoy for her collaboration in microbial analyses and Ms. Silvia Barañano of Pranas S.A. for the supply of raw material and for allowing the use of the industrial facilities.

\section{Funding}

This work was supported by the Consejo Nacional de Investigaciones Científicas y Técnicas (PIP $2013 \mathrm{~N}^{\circ} 0403$ and PIP 2016 $\mathrm{N}^{\circ}$ 0437), Agencia Nacional de Promoción Científica y Tecnológica, MINCyT (PICT $2015 \mathrm{~N}^{\circ}$ 2855) and Universidad Nacional de Mar del Plata (ING447/15).

\section{References}

Aponte, M., Blaiotta, G., Francesca, N., Moschetti, G., 2010. Could halophilic archaea improve the traditional salted anchovies (Engraulis encrasicholus L.) safety and quality? Lett. Appl. Microbiol. 51, 697-703.

Besteiro, I., Rodríguez, C.J., Tilve-Jar, C., Pascual, C., 2000. Selection of attributes for the sensory evaluation of anchovies during the ripening process. J. Sens. Stud. 15, 65-77.

Borgstrom, G. (Ed.), 1965. Fish as Food. New York and London Academic Press Inc (518 pp).

Campello, F., 1985. Approche microbiologique de l'anchoítage. In: Revue Travaux Inst Peches Maritimes. 47. pp. 217-226.

Coelho, A.M., Coelho, A.C., Góis, J., Pinto, M.L., Rodrigues, J., 2008. Multifactorial correspondence analysis of risk factors for sheep and goat brucellosis seroprevalence. Small Rumin. Res. 78 (1-3), 181-185.

Czerner, M., Yeannes, M.I., 2014. Bacterial contribution to salted anchovy (Engraulis anchoita Hubbs \& Marinni, 1935) ripening process. J. Aquat. Food Prod. Technol. 23, 102-114.

DasSarma, S., DasSarma, P., 2017. Halophiles. In: eLS. John Wiley \& Sons Ltd., Chichester. http://www.els.net. https://doi.org/10.1002/9780470015902 a0000394.pub4.

Durand, P., 1981. Etude de la fraction azotee soluble de l'anchois sale en tours maturation. Rev. Trav. Inst. Peches Marit. 45 (4), 271-281.

Escofier, B., Pagès, J., 1998. Analyses factorielles simples et multiples. Dunod, Paris.

Felix, M.L., Czerner, M., Ameztoy, I.M., Ramírez, E.E., Yeannes, M.I., 2016. Investigation of Halococcus morrhuae in salted-ripened anchovy products. Int. Food Res. J. 23 (6), $2668-2674$.

FIL IDF 73, 1974. International Standard. Milk and milk products. Brussels.

Filsinger, B., Barassi, C.A., Lupín, H.M., Trucco, R.E., 1982. An objective index for the evaluation of the ripening of salted anchovy. Int. J. Food Sci. Technol. 17 (2), $193-200$.

Filsinger, B.E., Barassi, C.A., Lupín, H.M., 1984. Formación de Nitrógeno Básico Volátil
Total durante la maduración de anchoíta (E. anchoita). Rev. Agroquím. Tecnol Aliment. 24 (4), 524-528.

Frost, S.C., Blackman, J.W., Ebeler, S.E., Heymann, H., 2018. Analysis of temporal dominance of sensation data using correspondence analysis on Merlot wine with differing maceration and cap management regimes. Food Qual. Prefer. 64, 245-252.

Geisen, R., Lücke, F.K., Kröckel, L., 1992. Starter and protective cultures for meat and meat products. Fleischwirtschaft 72, 894-898.

Gram, L., Dalgaard, P., 2002. Fish spoilage bacteria - problems and solutions. Curr. Opin. Biotechnol. 13, 262-266.

Gram, L., Huss, H.H., 1996. Microbiological spoilage of fish and fish products. Int. J. Food Microbiol. 33, 121-137.

Hernández-Herrero, M.M., Roig-Sagués, A.X., López-Sabater, E.I., Rodríguez-Jerez, J.J., Mora-Ventura, M.T., 1999a. Total volatile basic nitrogen and another physico-chemical and microbiological characteristics as related to ripening of salted anchovies. J. Food Sci. 67 (2), 2631-2640.

Hernández-Herrero, M.M., Roig-Sagués, A.X., López-Sabater, E.I., Rodríguez Jerez, J.J., Mora-Ventura, M.T., 1999b. Protein hydrolysis and proteinase activity during the ripening of salted anchovy (Engraulis encrasicholus L.). A microassay method for determining the protein hydrolysis. J. Agric. Food Chem. 47 (8), 3319-3324.

Holt, J.G., 1989. Archaeobacteria. In: Bergey, D.H., Holt, J.G., Krieg, N.R., Staley, J.T (Eds.), Bergey's Manual of Systematic Bacteriology. Vol. III. Williams \& Wilkins, Baltimore, MD, pp. 2171-2233.

Hugas, M., Monfort, J.M., 1997. Bacterial starter cultures for meat fermentation. Food Chem. 59 (4), 547-554.

Huss, H.H., Valdimarson, G., 1990. Microbiology of salted fish. Fish Technol. News 10 (1), 3-5.

ICMSF, 1983. Microorganismos de los Alimentos. In: Técnicas de Análisis Microbiológico. vol. I Acribia, Zaragoza.

Lee, S.H., Jung, J.Y., Jeon, C.O., 2015. Bacterial community dynamics and metabolite changes in myeolchi-aekjeot, a Korean traditional fermented fish sauce, during fermentation. Int. J. Food Microbiol. 203, 15-22.

Madureira, L.S., Castello, J.P., Prentice-Hernández, C., Queiroz, M.I., Espírito Santo, M.L., Ruiz, W.A., Raggi Abdallah, P., Hansen, J., Bertolotti, M.I., Manca, E., Yeannes, M.I., Avdalov, N., Fernández Amorín, S., 2009. Current and potential alternate food uses of the Argentine anchoita (Engraulis anchoita) in Argentina, Uruguay and Brazil. In: Hasan, M.R., Halwart, M. (Eds.), Fish as Feed Inputs for Aquaculture. Practices, Sustainability and Implications. FAO Fisheries Technical Paper, Rome.

Mc Faddin, J.F., 1980. Pruebas Bioquímicas para la Identificación de Bacterias de Importancia Clínica. Médica Panamericana, Buenos Aires.

Pérez, S., Barañano, S., Murialdo, S., Yeannes, M.I., 2016. In: Modificación de la flora microbiológica durante el salado de anchoíta (Engraulis anchoita). Proceedings of the FoodInnova 2014. pp. 455-464.

Perez, S., Ameztoy, I., Yeannes, M.I., 2017. In: Evaluación de la microflora en muestras de Engraulis anchoita en diferentes etapas del proceso de maduración. Proceedings of the XVI CYTAL. (In press).

Pons-Sánchez-Cascado, S., Veciana-Nogués, M.T., Bover-Cid, S., Mariné-Font, A., VidalCarou, M.C., 2005. Volatile and biogenic amines, microbiological counts, and bacterial amino acid decarboxylase activity through the salt ripening process of anchovies (Engraulis encrasicholus). J. Food Prot. 68 (8), 1683-1689.

R Core Team, 2014. R: A Language and Environment for Statistical Computing. R Foundation for Statistical Computing, Vienna. http://www.R-project.org/.

Ramette, A., 2007. Multivariate analyses in microbial ecology. FEMS Microbiol. Ecol. 62, 142-160.

Roh, S.W., Kim, K.H., Nam, Y.D., Chang, H.W., Park, E.J., Bae, J.W., 2009. Investigation 
of archaeal and bacterial diversity in fermented seafood using barcoded pyrosequencing. ISME J. 4 (1), 1-16.

Sehgal, S.N., Gibbons, N.E., 1960. Effect of some metal ions on the growth of Halobacterium cutilubrum. Can. J. Microbiol. 6, 165-169.

Steffánson, G., Guðmundsdóttir, G., 1995. Free Amino Acids and their Relationship to

Taste in (Salt) Ripened Pelagic Fish Species. Rf Report 91. Islandic Fish Laboratories.

Talon, R., Leroy, S., 2014. Fermented Meat Products and the Role of Starter Cultures.

Elsevier Ltd, INRA, Saint-Genès Champanelle.

Triqui, R., Reineccius, G.A., 1995. Flavor development in the ripening of anchovy (Engraulis encrasicholus L.). J. Agric. Food Chem. 43 (2), 453-458.
Ugarte, M., Militino, A., Arnholt, A., 2008. Probability and Statistics with R. Chapman \& Hall/CRC, New York.

Villar, M., Ruiz Holgado, A., Sanchez, J., Trucco, R., Oliver, G., 1985. Isolation and characterization of Pediococcus halophilus from salted anchovies (Engraulis anchoita). Appl. Environ. Microbiol. 49 (3), 664-666.

Yeannes, M.I., 1995. Histamina en productos pesqueros. In: Silvestre, A. (Ed.),

Toxicología de los Alimentos. Cap VII. Hemisferio Sur S.A., Buenos Aires, pp. 30-45.

Yu, X., Zhao, M., Hu, J., Zeng, S., Bai, X., 2012. Correspondence analysis of antioxidant activity and UV-vis absorbance of Maillard reaction products as related to reactants. LWT Food Sci. Technol. 46 (1), 1-9. 